\title{
ДЕТЕРМИНИРОВАНИЕ ИНСТИТУЦИОНАЛЬНОЙ СТРУКТУРЫ ВЫСОКОТЕХНОЛОГИЧНЫХ ОТРАСЛЕЙ ПРОМЫШЛЕННОСТИ
}

\author{
(C) 2020 Карлик Александр Евсеевич \\ доктор экономических наук, профессор, заведующий кафедрой экономики и управления предпри- \\ ятиями и производственными комплексами \\ Санкт-Петербургский государственный экономический университет, Россия, Санкт-Петербург \\ E-mail: Karlik1@mail.ru
}

\section{(c) 2020 Уманский Анатолий Михайлович}

соискатель кафедры экономики и управления предприятиями и производственными комплексами Санкт-Петербургский государственный экономический университет, Россия, Санкт-Петербург

E-mail: uam_777@mail.ru

В публикации автором представлены результаты детерминирования институциональной структуры высокотехнологичных отраслей промышленности. Исследование построено на теоретической платформе мезоэкономики. На основе статистического эксперимента развит метод картирования Schneider M.R. в части структуры индикаторов, определяющих границы институтов отрасли. Выделена оптимальная структура и пропорции высокотехнологичных отраслей промышленности.

Ключевые слова: экономика, промышленность, высокие технологии.

Актуальность и степень изученности проблемы.

Задача развития высокотехнологичного сектора является ключевой для стран, ориентированных на инновационные драйверы экономического роста. Развитие построено на интенсификации и экстенсификации производительные сил и производственных отношений высокотехнологичного сектора, а его динамика отражается рядом индикаторов: доля сектора в ВВП, в совокупном экспорте, товарообороте промышленности; наукоемкости отраслей сектора; численности специалистов занятых в НИОКР (относительно населения) и другими. Индикаторы выражают макроэкономическую позицию сектора в глобальной и национальных экономиках и объективно отражены в аналитических отчетах Мирового Банка*, UNIDO (Quarterly Report on Manufacturing, 2015-2019**), OECD (Science, Technology and Industry Outlook 2018 [1]), BCC Research Report Overview (2019 Manufacturing Research Review [2]), IQMS (What Drives Growth in Manufacturing, 2017***) и других. Поиск эндогенных факторов микроэкономического роста построен на кейсах высокотехнологичных предприятий (консолидировано в работах Хлебников К.В. [3], Чернов О.А., Михайлова Е.Л. [4],
Umble Е. J. и др. [5], Shih B. Ү. и др. [6], Chung Y.С. и др. [7] и других экономистов). Но изучение макрои микро- драйверов имеет ограничение в части описания структуры отраслей, взаимодействия субъектов, их пропорций, функций институтов инновационной и производственной деятельности, то есть, мезо- факторов экономического роста высокотехнологичных отраслей.

Именно поэтому современные исследования высокотехнологичного сектора ориентируются на теоретическую платформу «мезоэкономики» (Dopfer K. [8]). Объектом ее исследования являются состав и пропорции специализированных субъектов (институтов) и схемы их взаимодействия. В рамках данного направления исследований Paunescu M., Schneider M. [9] описали модели институциональной среды, обеспечивающие экономический рост отраслей. Dixon М. И др. [10] и Kleiner M.M. [11] исследовали иерархию контрактов высокотехнологичного сектора и выделили «экономическое ядро» взаимодействия институтов. Воуег R. [12] сформулировал стратегии развития институтов, обеспечивающие рост масштаба (товарооборота) отраслей. Научная дискуссия привела к формированию понятия «институционального капитала» (англ.institutional capital, HeniszW.J., Swaminathan

\footnotetext{
* Режим доступа: https://www.worldbank.org 22.02.2020.

** Режим доступа: https://www.unido.org/resources-statistics/quarterly-report-manufacturing 12.01.2020.

*** Режим доступа: https://www.iqms.com 22.12.2019.
} 
А. [13]), как совокупности институтов и их взаимодействия, составляющие которого описали Jackson G. и Deeg R. [14]. Методическая (инструментальная) часть мезоэкономики предложена Schneider M.R. [15] в форме «картирования» высокотехнологичных отраслей (англ.- mapping): выделения состава и пропорций институтов. Ограничением предложенного Schneider M.R. метода картирования является качественный характер критериев выделения институтов. Снятие данного ограничения, предложение объективных количественных подходов, позволит развить метод картирования Schneider M.R. и определить оптимальные пропорции институтов высокотехнологичного сектора.

\section{Исследовательские задачи.}

Автор сформулировал исследовательскую задачу как определение оптимального состава и пропорций институтов высокотехнологичного сектора промышленности через развитие метода картирования Schneider M.R. в части выделения количественных критериев детерминирования субъектов инновационной и производственной деятельности отраслей. Задача подразумевает следующую архитектуру исследования:

1. Выделить «эталонную» отрасль высокотехнологичного сектора, состав и пропорции которой определяются оптимальными;

2. Определить взаимосвязанные показатели экономического развития отрасли, которые определяются критериями детерминирования границ институтов;

3. На основе показателей картировать эталонную отрасль - выделить институты и описать их функции в высокотехнологичной отрасли;

4. Формализовать оптимальные пропорции институтов высокотехнологичной отрасли.

\section{Результаты эксперимента и анализ.}

В качестве «эталонной» высокотехнологичной отрасли автором определена фармацевтическая промышленность Европы (интегрированная в странах Евросоюза и Восточной Европы). Глобальный лидер по объемам в международном товарообороте (табл. 1) с объективной экономической эффективностью и сформированными в результате самоорганизации пропорциями институтов инновационной (НИОКР) и производственной деятельности. Данная отрасль с одной стороны принимается как объект для (практический аспект) поиска институционального оптимума, с другой (теоретический аспект) - детерминирования эконометрических индикаторов разделения институциональных групп высокотехнологичного сектора.

Автором сформирована выборка из 4629 фармацевтических предприятий Европы фармацевтической отрасли (NACE Rev 2) по базе данных Aмadeus. Выбор базы данных обусловлен наличием в ее составе малых и средних предприятий изучаемой высокотехнологичной отрасли, что позволяет картировать не только корпоративный производственный сегмент (как это представлено у Henisz W. J., Swaminathan A. [13]), Jackson G. и Deeg R [14], Schneider M. R. [15]), но и малые инновационные предприятия, инновационную инфраструктуру, подрядчиков НИОКР и другие. Что в свою очередь, в картировании позволит отразить все предприятия, включенные в инвестиционный, научно-исследовательский, производственный и маркетинговый циклы высокотехнологичного сектора. Каждое предприятие в выборке описано по финансовоэкономическим показателям (МСФО 2018 год): OR - операционный доход; NE - списочная численность сотрудников; BvD - индекс неза-

Таблица 1. Данные экспорта и импорт глобального фармацевтического рынка (млрд. USD). По данным UNCTAD.

\begin{tabular}{|l|l|l|l|}
\hline Страны & Экспорт & Импорт & Баланс \\
\hline Германия & $\mathbf{8 4 , 7}$ & $\mathbf{5 3 , 7}$ & $\mathbf{3 1}$ \\
\hline Швейцария & $\mathbf{7 1 , 7}$ & $\mathbf{2 9 , 3}$ & $\mathbf{4 2 , 4}$ \\
\hline США & 49,7 & 99,7 & -50 \\
\hline Бельгия & 45,7 & 36,7 & 9 \\
\hline
\end{tabular}

Режим доступа: https://unctad.org 22.10.2019. 
висимости акционерного капитала*; NI - прибыль предприятия до выплаты дивидендов; ROE - рентабельность собственного капитала предприятия; TAS - активы; PM - норма прибыли. Данные показатели определены как гипотетические в поиске эконометрических индикаторов разделения институциональных групп высокотехнологичного сектора. Критерием принадлежности индикатора системе детерминирования институциональных групп автором определена их взаимосвязь (высокие значения корреляции по шкале Чеддока), что академически традиционно для поиска эконометрических моделей.

Соответственно, в рамках выборки автором проведён кросскорреляционный анализ показателей, результаты которого представлены в таблице 2.
Корреляционный анализ позволил выделить 3 взаимосвязанных переменных (рис. 1), выражающих институциональную структуру высокотехнологичных отраслей: операционный доход, балансовая стоимость активов, списочная численность сотрудников предприятия (по полному кругу).

Представление индикаторы являются теоретической платформой количественного картирования институтов высокотехнологичного сектора. Данное решение рассматривается как научный результат, развитие теоретической платформы метода картирования институциональной структуры Schneider M.R. применительно к высокотехнологичному сектору.

На основе развитого метода автор произвел картирование эталонной отрасли. В поле операционного дохода и величины активов автор

* Классификация Moody’s Analytics Company по уровню концентрации акционерного капитала по структуре: численности и величине долей инвесторов (от А+ до D). Режим доступа: https://www.bvdinfo.com 12.11.2019.

Таблица 2. Корреляционного анализа гипотетических переменных, выражающих институциональную структуру эталонной высокотехнологичной отрасли.

\begin{tabular}{|l|r|r|r|r|r|r|}
\hline & \multicolumn{1}{|c|}{ OR } & \multicolumn{1}{c|}{ NE } & \multicolumn{1}{c|}{ NI } & \multicolumn{1}{c|}{ ROE } & \multicolumn{1}{c|}{ TAS } & PM \\
\hline NE & $\mathbf{0 , 9 0 1 5 * * *}$ & & & & & \\
\hline NI & $0,4862 * *$ & $0,4524 * *$ & & & & \\
\hline ROE & 0,0150 & 0,0103 & 0,0314 & & & \\
\hline TAS & $\mathbf{0 , 9 1 1 1 * * *}$ & $\mathbf{0 , 8 7 7 8 * * *}$ & 0,4509 & 0,0041 & & \\
\hline PM & 0,0200 & 0,0178 & 0,0608 & 0,4021 & 0,0148 & \\
\hline BvD & $-0,0489$ & $-0,0646$ & $-0,0133$ & 0,0026 & $-0,0562$ & 0,0167 \\
\hline
\end{tabular}

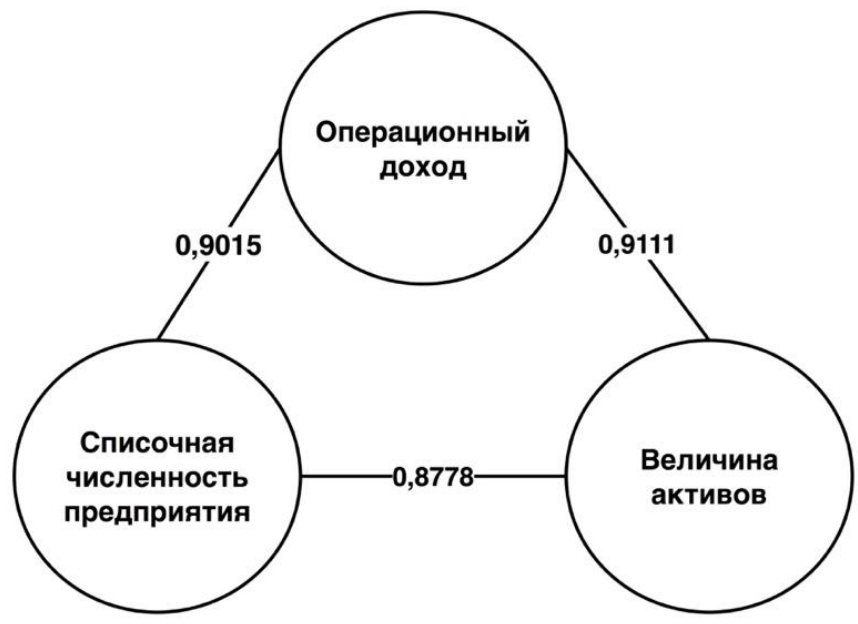

Рис. 1. Индикаторы институциональной структуры высокотехнологичного сектора. 
обнаруживает границы кластеров, сегментов специализированных субъектов высокотехнологичной отрасли, рис. 2, табл. 3.

Кейс методом по записям в базе данных Aмadeus классифицированы виды деятельности субъектов (классификатор NACE Rev 2), представляющие институциональные группы.

Соответственно автором выделено 5 специализированных видов деятельности (институциональных групп, табл. 4,5), взаимодействие которых позволяет реализовать полный цикл инновационной, производственной и коммерческой (маркетинговой) деятельности высокотехнологичной отрасли. Как видно, представленные институты связаны в вертикальной иерархии формирования добавленной стоимо- сти конечной (потребительской) высокотехнологичного продукции, объективно отличающейся от средне- и низкотехнологичной значительной наукоемкостью, инновационностью.

Применительно к выделенным институциональным группам автором проведен вертикальный анализ распределения 4 показателей (численность субъектов, операционный доход, величина активов и списочная численность персонала отрасли) в исходной выборке. Относительные пропорции групп позволяют судить об оптимальных отношениях, обеспечивающих эффективность и экономический рост высокотехнологичной отрасли при признании «эталонной» позиции выбранного объекта исследования, табл. 5.

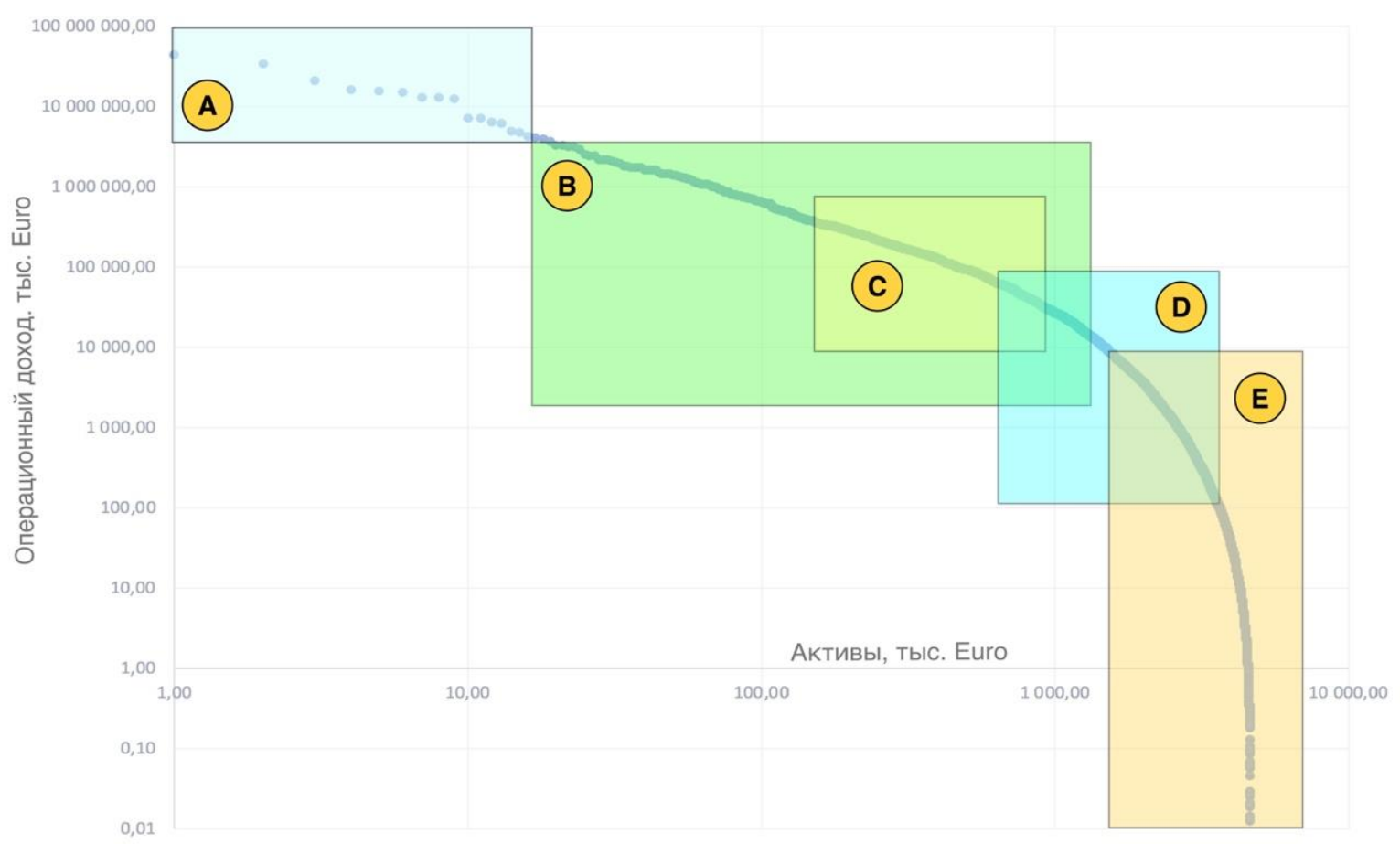

Pис. 2. Картирование институтов высокотехнологичного сектора. Описание сегментов в табл. 3.

Таблица 3. Разделение институтов высокотехнологичных отраслей сектора в границах операционного дохода и величины активов.

\begin{tabular}{|l|c|c|}
\hline \multirow{2}{*}{ Институциональная группа } & \multicolumn{2}{|c|}{ Границы, тыс. евро } \\
\cline { 2 - 3 } & Опер. доход & Активы \\
\hline А Инвесторы & $8000-100000000$ & $1-20$ \\
\hline В Лаборатории прикладных НИР & $2000-8000$ & $20-1100$ \\
\hline С Специализированные лаборатории & $10000-90000$ & $120-900$ \\
\hline D Производители конечной продукции & $100-100000$ & $800-6000$ \\
\hline Е Производители компонентов & $0,01-10000$ & $2000-9000$ \\
\hline
\end{tabular}


Таблица 4. Специализация и функции институтов высокотехнологичной отрасли.

\begin{tabular}{|l|l|}
\hline $\begin{array}{l}\text { Институцио- } \\
\text { нальная } \\
\text { группа }\end{array}$ & Специализация, функция в отрасли \\
\hline А Инвесторы & $\begin{array}{l}\text { Предприниматель, инвестор, инициатор инновационных } \\
\text { проектов. Функция управления инвестиционными и опера- } \\
\text { ционными финансовыми потоками во всей вертикале взаи- } \\
\text { модействия субъектов отрасли, рис. \#. Несет предпринима- } \\
\text { тельские, маркетинговые риски. }\end{array}$ \\
\hline $\begin{array}{l}\text { В Лаборато- } \\
\text { рии приклад- } \\
\text { ных НИР }\end{array}$ & $\begin{array}{l}\text { Специализированный (профилю отрасли) научно-техниче- } \\
\text { дования. Является генеральным подрядчиком цикла НИОКР } \\
\text { в инновационном процессе. }\end{array}$ \\
\hline $\begin{array}{l}\text { С Специали- } \\
\text { зированные } \\
\text { лаборатории }\end{array}$ & $\begin{array}{l}\text { Обще профильные (межотраслевые) субъекты, реализующие } \\
\text { специализированные операции цикла НИОКР по контракту с } \\
\text { группой В. В международной практике также относится к ин- } \\
\text { ституту: «исследовательская инфраструктура». Включает } \\
\text { также сертифицирующие и тестовые лаборатории (разреши- } \\
\text { тельные организации). }\end{array}$ \\
\hline $\begin{array}{l}\text { D Произво- } \\
\text { дители } \quad \text { ко- } \\
\text { нечной пр- } \\
\text { дукции }\end{array}$ & $\begin{array}{l}\text { Специализированный (профилю отрасли) субъект производ- } \\
\text { ства, массового тиражирования конечной продукции. Как } \\
\text { правило, выполняет функцию сбыта по договору с инвесто- } \\
\text { ром (А). }\end{array}$ \\
\hline $\begin{array}{l}\text { Е Произво- } \\
\text { дители ком- } \\
\text { понентов }\end{array}$ & $\begin{array}{l}\text { Обще профильные (межотраслевые) субъекты, реализующие } \\
\text { производсво сырья и компонентов для основного производ- } \\
\text { ственного цикла (D). }\end{array}$ \\
\hline
\end{tabular}

Таблица 5. Оптимальные пропорции институтов высокотехнологичной отрасли.

\begin{tabular}{|l|c|c|c|c|}
\hline $\begin{array}{l}\text { Институциональная } \\
\text { группа }\end{array}$ & $\begin{array}{l}\text { Численность } \\
\text { предприятий }\end{array}$ & $\begin{array}{l}\text { Операцион- } \\
\text { ный доход }\end{array}$ & $\begin{array}{l}\text { Ак- } \\
\text { тивы }\end{array}$ & $\begin{array}{l}\text { Списочная } \\
\text { численность }\end{array}$ \\
\hline А Инвесторы & 3,2 & 22,4 & 9,2 & 0,8 \\
\hline $\begin{array}{l}\text { В Лаборатории при- } \\
\text { кладных НИР }\end{array}$ & 22,4 & 32,4 & 7,4 & 44,1 \\
\hline $\begin{array}{l}\text { С Специализирован- } \\
\text { ные лаборатории }\end{array}$ & 4,3 & 7,2 & 11,3 & 9,3 \\
\hline $\begin{array}{l}\text { D Производители ко- } \\
\text { нечной продукции }\end{array}$ & 41,7 & 26,8 & 34,5 & 27,4 \\
\hline $\begin{array}{l}\text { Производители } \\
\text { компонентов }\end{array}$ & 28,4 & 11,2 & 37,6 & 18,4 \\
\hline
\end{tabular}

Выделение оптимальных пропорций (табл. 5) институциональной структуры высокотехнологичных отраслей является заключительной частью эксперимента, ответом на генеральную исследовательскую задачу.

Выводы и заключение.

Таким образом, представлены результаты авторского эксперимента, имеющего 2 компоненты. Теоретическая компонента представлена развитием метода картирования Schneider M.R. в части детерминирования количественных переменных, выражающих институциональную структуру высокотехнологичного сектора. Практическая часть представлена количественными распределениями, выражающими оптимальную структуру субъектов высокотехнологичного сектора.

Ограничением (и как следствие, направле- 
ние дальнейшего исследования) является изучение одной «эталонной» высокотехнологичной отрасли (фармацевтическая Европы). Автор до- пускает вариативность пропорций (но не состава) институциональных групп применительно к другим отраслям высокотехнологичного сектора.

\section{Библиографический список}

1. OECD: Science, Technology and Industry Outlook.-OECD, 2016.

2. 2019 Manufacturing Research Review. BCC Research Report Overview, 2020.

3. Хлебников К.В. Параметры инновационного цикла высокотехнологичного предприятия: этапы, стоимость, длительность, персонал / К. В. Хлебников // Экономические науки. 2016. - № 10(143). - 0,7 п.л.

4. Чернова О.А., МихайловаЕ.Л. Затраты на НИОКР как фактор развития потенциала капитализации высокотехнологичных компаний. Азимут научных исследований: экономика и управление. 2019. Т. 8. № 1 (26). С. $226-228$

5. Umble, E. J., Haft, R. R., Umble, M. M. Enterprise resource planning: Implementation procedures and critical success factors. European Journal of Operational Research, 2003.

6. Shih, B. Y., Chen, C. Y., Chen, Z. S. An empirical study of an internet marketing strategy for search engine optimization. Human Factors and Ergonomics in Manufacturing, 2013.

7. Chung, Y. C., Hsu, Y. W., Tsai, C.H.An empirical study on the correlation between Critical DFSS success factors, DFSS implementation activity levels and business competitive advantages in Taiwan's high-tech manufacturers. Total Quality Management and Business Excellence, 2008.

8. Dopfer, K. The Origins of Meso Economics Schumpeter's Legacy. In the Papers on Economics and Evolution. Jena, Germany: Evolutionary Economics Group 2006.

9. Paunescu, M., Schneider, M. More on testing the varieties of capitalism. Schmollers Jahrbuch: Zeitschrift für Wirtschafts- und Sozialwissenschaften, 2005, 125(2): 323-325.

10. Dixon, M., Roscigno, V. J., Hodson, R. Unions, solidarity, and striking. Social Forces, 2004, 83(1): 3-33.

11. Kleiner, M. M. Intensity of management resistance: Understanding the decline of unionization in the private sector. Journal of Labor Research, 2004 22(3): 519-540.

12. Boyer, R. New growth regimes, but still institutional diversity. Socio-Economic Review, 2004, 2(1): 1-32.

13. Henisz, W. J., Swaminathan, A. Institutions and international business. Journal of International Business Studies, 2008. 39(4): 537-539.

14. Jackson, G., Deeg, R.Comparing capitalisms: Understanding institutional diversity and its implications for international business. Journal of International Business Studies, 2008. 39(4): 540-561.

15. Schneider, M. R., Schulze-Bentrop, C., Paunescu, M. Mapping the institutional capital of high-tech firms: A fuzzy-set analysis of capitalist variety and export performance. Journal of International Business Studies, 2010. 